\title{
Identifikasi Hama Kelapa Sawit menggunakan Metode Certainty Factor
}

\author{
Joan Angelina Widians ${ }^{\text {a, }, *}$ dan Farahdina Nur Rizkyani a,2 \\ ${ }^{a}$ Universitas Mulawarman, Jl. Kuaro I, Kampus Sempaja, Samarinda, Kalimantan Timur 75119 \\ 1'1angel.unmul@gmail.com; ${ }^{2}$ farahdinarizky16@gmail.com \\ * corresponding author
}

\section{INFORMASI ARTIKEL ABSTRAK}

Dikirim: 26 Februari 2020

Diulas: 7 April 2020

Direvisi: 8 April 2020

Diterbitkan: 27 April 2020

Kata Kunci:

Hama tanaman kelapa sawit

Sistem pakar

Certainty Factor

Forward Chaining

Keywords:

The pests of palm oil

Expert system

Certainty Factor

Forward Chaining

\begin{abstract}
Minimnya pengetahuan petani kelapa sawit dan masyarakat umum tentang hama pada tanaman kelapa sawit akan berakibat kurangnya hasil panen pada tanaman tersebut. Hal ini menimbulkan dampak banyak petani kelapa sawit yang menebang pohon sebagai upaya pemberantasan hama. Keterbatasan seorang pakar membuat penanganan serangan hama tanaman kelapa sawit menjadi sulit dilakukan, oleh karena itu dibutuhkan adanya sebuah sistem pakar yang mampu mengidentifikasikan hama tanaman kelapa sawit serta cara pengendaliannya berdasarkan pengetahuan yang diberikan langsung oleh seorang ahli. Inferensi yang digunakan adalah forward chaining dengan cara menelusuri aturan-aturan berdasarkan jawaban yang diberikan oleh pengguna. Jawaban pengguna kemudian dihitung menggunakan metode Certainty Factor. Hasil perhitungannya yaitu berupa nilai persentase keyakinan dan pengguna dapat langsung mengetahui jenis hama yang teridentifikasi dan cara pengendaliannya. Hasil pengujian pada penelitian ini didapatkan 7 (tujuh) hama yang menyerang kelapa sawit, yaitu ulat api Setothosea asigna ulat bulu Dasychira inclusa, ulat kantong Metisa plana, kumbang tanduk Oryctes rhinoceros rayap Coptotermes curvignathus, tikus belukar Rattus tiomanicus dan babi hutan Sus crofa. Serangan hama terbesar adalah hama rayap Coptotermes curvignathus sebesar $88,8 \%$ pada tanaman kelapa sawit.
\end{abstract}

\section{ABSTRACT}

The lack of knowledge of palm oil farmers and general public about pests in palm oil plants will result in a lack of crop yields on these plants. The resulted in the impact of many palm oil farmers who cut down trees as an effort to eradicate of pests. The limitations of an experts makes handling palm oil plan pests difficult so it is necessary to have an experts system that is able to identify pests of palm oil and how to control them based on knowledge given directly by human experts. The inference is Forward chaining by tracing the rules based on the answers of users. And then calculated by Certainty Factor method. The result of calculation is in the form of a percentage value of confidence and user can immediately find out the type of pests identified and how to control it. This research found 7 (seven) types of pests that attack palm oil are fire caterpillar Setothosea asigna, caterpillars Dasychira inclusa, bag caterpillar Metisa plana, horn beetle Oryctes rhinoceros, termite Coptotermes curvignathus, wild rat Rattus tiomanicus, dan wild pig Sus crofa. The biggest pest attact on palm oil is Termite Coptotermes Curvignathus is $88,8 \%$

This is an open access article under the CC-BY-SA license.

\section{Pendahuluan}

Kelapa sawit (Elaeis guineensis jacq) merupakan salah satu tumbuhan perkebunan yang memiliki prospek industri yang baik dipasar lokal maupun pasar dunia. Saat ini perkebunan kelapa sawit di Indonesia sudah semakin berkembang dan menjadikan Indonesia sebagai penghasil utama minyak sawit yang memproduksi lebih dari 44\% minyak sawit dunia [1] [2]. Selain itu perkebunan kelapa sawit hampir ada di seluruh bagian kepulauan Nusantara, salah satunya pada Provinsi Kalimantan Timur. Potensi produksi kelapa sawit di Kalimantan Timur sangat besar dari tahun 2008 sebesar 1.664.311 Ton, di tahun 2013 sebesar 6.901.602 Ton, serta setiap tahun produksi kelapa sawit selalu meningkat. Dapat disimpulkan bahwa 
perkembangan penanaman kelapa sawit di Kalimantan Timur dari tahun 2008 sampai 2016 terjadi peningkatan [3] [4] .

Hama merupakan salah satu organisme pengganggu tanaman yang menjadi faktor penting yang harus diperhatikan dalam perkebunan kelapa sawit. Perbedaan hama dari penyakit adalah kerusakan yang ditimbulkan. Hama menimbulkan kerusakan fisik seperti gesekan, tusukan dan lain-lain. Sedangkan penyakit menimbulkan gangguan fisiologis pada tanaman [5]. Kerusakan yang ditimbulkan hama cukup besar, baik penurunan produksi maupun kematian tanaman. Jenis kerusakan hama dapat berakibat langsung pada komoditas, seperti serangan pada buah, daun, batang dan akar. Hama dapat menyerang tanaman mulai pembibitan, tanaman belum menghasilkan (TBM) hingga tanaman menghasilkan (TM), dimana daya rusak masing-masing hama berbeda satu sama lain. Salah satu aspek pemeliharaan tanaman yang perlu diperhatikan dalam kegiatan budidaya kelapa sawit adalah pengendalian hama. Pengendalian hama yang baik dapat meningkatkan produksi dan produktivitas tanaman kelapa sawit [6] [7] [8].

Pada tahun 2018 luas areal kelapa sawit di Kalimantan Timur telah mencapai 1.199.407 Ha dengan produksi Tandan Buah Segar (TBS) sebesar 13.398.348 ton. Namun peningkatan luas areal dan produktifitas perkebunan kelapa sawit pada Kalimantan Timur tentu tidak terlepas dari beberapa kendala seperti rata-rata tanaman yang melewati umur produktif 60 tahun ke atas dan adanya Organisme Pengganggu Tumbuhan (OPT) seperti Ulat Pemakan Daun kelapa Sawit (UPDKS) ulat api, ulat kantong dan ulat bulu. Hama serangga seperti kumbang tanduk dan hama mamalia seperti tikus dan babi hutan yang pada umumnya menyerang perkebunan kelapa sawit di Kalimantan Timur [5] .

Sistem pakar adalah suatu sistem komputer yang mengadopsi kemampuan dari seorang pakar atau seorang ahli. Sistem pakar sendiri bertujuan untuk membantu seseorang yang bukan pakar dalam menyelesaikan masalah yang memerlukan hadirnya seorang pakar. Sistem pakar biasanya menangani masalah yang kompleks yang membutuhkan implementasi pakar dan digunakan untuk menyelesaikan masalah dengan menggunakan komputer dengan model penalaran manusia dan mencapai kesimpulan yang sama dengan dicapai oleh seorang pakar jika berhadapan dengan suatu masalah. Sistem pakar sendiri merupakan sistem berbasis komputer yang menggunakan pengetahuan, fakta dan teknik penalaran dalam memecahkan suatu masalah yang biasanya hanya dapat dipecahkan oleh seorang pakar dalam bidang tersebut. Kelebihan dari sistem pakar adalah sebagai asisten para ahli sehingga meringankan pekerjaan para ahli, yang dapat menghemat waktu dalam mengambil keputusan [9] [10].

Ciri-ciri dari sistem pakar adalah strategi dalam ilmu pengetahuan yang berhubungan dengan suatu penemuan (heuristik) yang dikembangkan untuk menyelesaikan masalah yang khusus. Heuristiknya dan sifatnya yang berdasarkan pengetahuan, umumnya sistem pakar memiliki informasi yang handal baik dalam menampilkan langkah-langkah maupun dalam menjawab pernyataan tentang proses penyelesaiannya dan mudah untuk dimodifikasi [11] [12] Pada penelitian sistem pakar ini, data dan informasi didapatkan dari Bapak Mulyadi sebagai seorang pakar hama dan penyakit di UPTD Pengembangan Perlindungan Tanaman Perkebunan Kaltim dan Bapak Dr. Abdul Sahid, SP., MP sebagai seorang dosen Fakultas Pertanian Universitas Mulawarman yang memiliki bidang penelitian hama pada kelapa sawit. Menurut data rekapitulasi serangan OPT pada tahun 2017 dan 2018 yang diperoleh dari Dinas Perkebunan Provinsi Kalimantan Timur, tercatat serangan hama terjadi pada wilayah diantaranya adalah Kutai Timur, Kutai Kartanegara, Berau, Bontang, Samarinda dan Penajam Paser Utara. Serangan hama terbesar terjadi pada tahun 2017 di wilayah Penajam Paser Utara dengan serangan seluas 39,45 hektar yang diserang oleh hama tikus dan babi hutan. Terdapat beberapa jenis hama yang paling banyak menyerang perkebunan kelapa sawit di Provinsi Kalimantan Timur yaitu, hama mamalia seperti tikus dan babi hutan, serta hama serangga seperti kumbang tanduk dan ulat pemakan daun kelapa sawit (UPDKS) yaitu ulat api, ulat kantong dan ulat bulu.

\section{Metode Penelitian}

Sistem pakar identifikasi hama kelapa sawit ini menggunakan metode Certainty Factor. Metode Certainty Factor digunakan untuk menghitung factor kepastian hama yang menyerang tanaman kelapa sawit di Provinsi Kalimantan Timur. Metode Certainty Factor memiliki konsep yang bertujuan untuk menampung ketidakpastian dari seorang pakar [9]. Certainty Factor menyatakan kepercayaan dalam sebuah kejadian (fakta atau hipotesis) berdasarkan bukti atau penilaian dari pakar [13].

Certainty Factor didefinisikan dengan persamaan (1).

$$
C F[h, e]=M B[h, e]-M D[h, e]
$$

Dimana

$C F[h, e] \quad$ : Faktor Kepastian

$M B[h, e] \quad$ : Ukuran kepercayaan atau tingkat keyakinan terhadap hipotesis $\mathrm{H}$, jika diberikan atau dipengaruhi evidence $\mathrm{E}$ (antara $0-1$ )

$M D[h, e] \quad$ : Ukuran ketidakpercayaan atau tingkat ketidakyakinan terhadap hipotesis $\mathrm{H}$, jika diberikan atau dipengaruhi evidence $\mathrm{E}$ (antara $0-1$ ) 
Ada tiga hal yang mungkin terjadi pada Certainy Factor, yaitu [14]:

1. Beberapa evidence dikombinasikan untuk menentukan Certainty Factor dari suatu hipotesis. Jika $e 1$ dan $e 2$ adalah observasi, maka:

$$
\begin{aligned}
& M B\left[h, e_{1} \wedge e_{2}\right]=\left\{\begin{array}{cc}
0 & c \\
M B\left[h, e_{1}\right]+M B\left[h, e_{2}\right] .\left(1-M B\left[h, e_{1}\right]\right) & M D\left[h, e_{1} \wedge e_{2}\right]=1 \text { lainnya } \\
0 &
\end{array} \quad \begin{array}{cc}
M B\left[h, e_{1} \wedge e_{2}\right]=1 \text { lainnya } \\
M D\left[h, e_{1} \wedge e_{2}\right]=M D\left[h, e_{2}\right] .\left(1-M D\left[h, e_{1}\right]\right)
\end{array}\right.
\end{aligned}
$$

2. Certainty Factor dihitung dari kombinasi beberapa hipotesis. Jika h1 dan h2 adalah hipotesis, maka:

$$
\begin{aligned}
& M B\left[h_{1} \wedge h_{2}, e\right]=\min \left(M B\left[h_{1}, e\right], M B\left[h_{2}, e\right]\right) \\
& M B\left[h_{1} \wedge h_{2}, e\right]=\max \left(M B\left[h_{1}, e\right], M B\left[h_{2}, e\right]\right) \\
& M D\left[h_{1} \wedge h_{2}, e\right]=\min \left(M D\left[h_{1}, e\right], M D\left[h_{2}, e\right]\right) \\
& M D\left[h_{1} \wedge h_{2}, e\right]=\max \left(M D\left[h_{1}, e\right], M D\left[h_{2}, e\right]\right)
\end{aligned}
$$

3. Beberapa aturan yang saling bergandengan, ketidakpastian dari suatu aturan menjadi input untuk aturan yang lainnya, maka persamaannya lihat persamaan (2).

$$
M B[h, s]=M B^{\prime}[h, s] * \max (0, C F[s, e])
$$

Dalam aturan dengan bukti tunggal $e$ (single evidence $e$ ) dan hipotesis tunggal $h$, di mana rumus Certainty Factor dapat dilihat persamaan (3).

$$
C F[h, e]=C F(e) x C F(\text { rule })
$$

Dimana:

$C F$ (rule) ditentukan oleh para ahli atau pakar.

$C F(e)$ ditentukan oleh pengguna saat berkonsultasi dengan system

Forward Chaining atau runut maju adalah teknik pencarian yang dimulai dengan fakta yang diketahui kemudian mencocokkan fakta-fakta tersebut dengan bagian IF dari rules IF - THEN. Jika ada suatu fakta yang cocok dengan bagian IF, maka rule tersebut dieksekusi. Bila rule tersebut dieksekusi, maka sebuah fakta baru (bagian THEN) ditambahkan ke dalam database [13] [15]. Penelusuran metode Forward Chaining ditunjukkan pada Gambar 1.

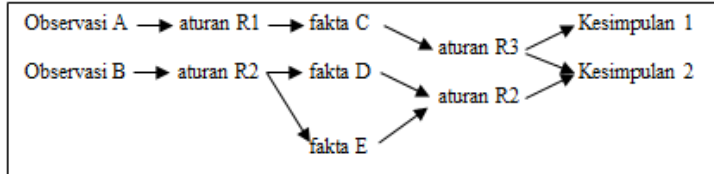

Gambar 1. Proses Penelusuran Forward Chaining

Runut maju merupakan metode inferensi menggunakan himpunan aturan kondisi-aksi. Dalam metode ini, data digunakan untuk menemukan aturan mana yang akan dijalankan. Metode inferensi ini cocok dilakukan untuk menangani pengendalian (controlling) dan peramalan (prognosis) [15].

\section{Hasil dan Pembahasan}

Sistem pakar identifikasi hama kelapa sawit dengan menggunakan metode Certainty Factor dapat mengidentifikasi 7 jenis hama pada kelapa sawit di provinsi Kalimantan Timur dan terdapat total keseluruhan 42 gejala. Sistem ini menggunakan metode Certainty Factor atau faktor kepastian untuk mendapatkan nilai persentase kepastian pada setiap hama yang menyerang. Tujuh hama yang menyerang perkebunan kelapa sawit di provinsi Kalimantan Timur disajikan dalam Tabel 1.

Tabel 1. Jenis Hama

\begin{tabular}{|l|l|}
\hline \multicolumn{1}{|c|}{ Kode Hama } & \multicolumn{1}{|c|}{ Jenis } \\
\hline H1 & Ulat Api Setothosea asigna \\
\hline H2 & Ulat Bulu Dasychira inclusa \\
\hline H3 & Ulat Kantong Metisa plana \\
\hline H4 & Kumbang Tanduk Oryctes rhinoceros \\
\hline H5 & Rayap Coptotermes curvignathus \\
\hline H6 & Tikus Belukar Rattus tiomanicus \\
\hline H7 & Babi Hutan Sus crofa \\
\hline
\end{tabular}


Ada 42 gejala yang teridentifikasi yang telah dipetakan kedalam bentuk Decision Table untuk memetakan data gejala dan hama pada kelapa sawit. Perhitungan manual dilakukan untuk mendapatkan hasil akhir yang sesuai dengan nilai MB (measure of believe) atau nilai kepercayaan dan nilai MD (measure of disbelieve) atau nilai ketidakpercayaan, yang telah ditentukan oleh pakar. Setiap gejala yang dipilih oleh pengguna akan diproses menggunakan metode perhitungan Certainty Factor (faktor kepastian). Gejala yang dipilih akan di proses pada semua kondisi hama yang menyerang pada kelapa sawit sehingga akan diketahui kondisi mana yang lebih tepat yang dialami oleh kelapa sawit. Nilai kepercayaan dan ketidakpercayaan terhadap hama diperoleh saat melakukan pengumpulan data di lapangan dan divalidasi oleh seorang ahli yaitu bapak Dr. Abdul Sahid, SP., MP. Berikut dijelaskan perhitungan manual untuk serangan hama pada tanaman kelapa sawit. Diketahui bahwa ada beberapa gejala yang terjadi pada tanaman kelapa sawit, antara lain gejala : [G03] Produksi tanaman menurun akibat tandan tidak berproduksi dengan baik $\wedge$ [G17] Kondisi batang tidak utuh atau rusak $\wedge$ [G24] Batang pohon rusak hingga membusuk $\wedge$ [G25] Akar pada tanaman muda terlebih di lahan gambut mengalami kerusakan $\wedge$ [G26] Daun berubah warna menjadi coklat dan mengering $\wedge$ [G27] Bibit layu pada bagian pucuk atau mati karena rusaknya akar $\wedge$ [G28] Terdapat alur tanah di permukaan tanah $\wedge$ [G29] Terdapat alur tanah di permukaan batang $\wedge$ [G30] Terdapat alur tanah di tandan buah. Perhitungan keseluruhan nilai MB (measure of believe) dari setiap gejala menggunakan persamaan (4).

$$
M B\left[h, e_{1} \wedge e_{2}\right]=\left\{\begin{array}{c}
0 \\
M B\left[h, e_{1}\right]+M B\left[h, e_{2}\right] .\left(1-M B\left[h, e_{1}\right]\right)
\end{array}\right.
$$

1. $[\mathrm{G} 03] \wedge[\mathrm{G} 17]$

$\mathrm{MB}=0.7+0.7 *(1-0.7)=0.91$

2. $[\mathrm{G} 03] \wedge[\mathrm{G} 17] \wedge[\mathrm{G} 24]$

$\mathrm{MB}=0.91+0.7 *(1-0.91)=0.973$

3. $[\mathrm{G} 03] \wedge[\mathrm{G} 17] \wedge[\mathrm{G} 24] \wedge[\mathrm{G} 25]$

$\mathrm{MB}=0.973+0.8 *(1-0.973)=0.9946$

4. $[\mathrm{G} 03] \wedge[\mathrm{G} 17] \wedge[\mathrm{G} 24] \wedge[\mathrm{G} 25] \wedge[\mathrm{G} 26]$

$\mathrm{MB}=0.9946+0.7 *(1-0.9946)=0.99838$

5. $[\mathrm{G} 03] \wedge[\mathrm{G} 17] \wedge[\mathrm{G} 24] \wedge[\mathrm{G} 25] \wedge[\mathrm{G} 26] \wedge[\mathrm{G} 27]$

$\mathrm{MB}=0.99838+0.8 *(1-0.99838)=0.999676$

6. $[\mathrm{G} 03] \wedge[\mathrm{G} 17] \wedge[\mathrm{G} 24] \wedge[\mathrm{G} 25] \wedge[\mathrm{G} 26] \wedge[\mathrm{G} 27] \wedge[\mathrm{G} 28]$

$\mathrm{MB}=0.999676+0.9 *(1-0.999676)=0.9999676$

7. $[\mathrm{G} 03] \wedge[\mathrm{G} 17] \wedge[\mathrm{G} 24] \wedge[\mathrm{G} 25] \wedge[\mathrm{G} 26] \wedge[\mathrm{G} 27] \wedge[\mathrm{G} 28] \wedge[\mathrm{G} 29]$

$\mathrm{MB}=0.9999676+0.9 *(1-0.9999676)=0.99999676$

8. $[\mathrm{G} 03] \wedge[\mathrm{G} 17] \wedge[\mathrm{G} 24] \wedge[\mathrm{G} 25] \wedge[\mathrm{G} 26] \wedge[\mathrm{G} 27] \wedge[\mathrm{G} 28] \wedge[\mathrm{G} 29] \wedge[\mathrm{G} 30]$

$\mathrm{MB}=0.99999676+0.9 *(1-0.99999676)=0.999999676$

Selanjutnya dilakukan perhitungan keseluruhan nilai MD (measure of disbelieve) dari setiap gejala menggunakan persamaan (5).

$$
M D\left[h, e_{1} \wedge e_{2}\right]=\left\{\begin{array}{c}
0 \\
M D\left[h, e_{1}\right]+M D\left[h, e_{2}\right] .\left(1-M D\left[h, e_{1}\right]\right)
\end{array}\right.
$$

1. $[\mathrm{G} 17] \wedge[\mathrm{G} 24]$

$\mathrm{MD}=0.3+0.3 *(1-0.3)=0.51$

2. $[\mathrm{G} 17] \wedge[\mathrm{G} 24] \wedge[\mathrm{G} 25]$

$\mathrm{MD}=0.51+0.3 *(1-0.51)=0.657$

3. $[\mathrm{G} 17] \wedge[\mathrm{G} 24] \wedge[\mathrm{G} 25] \wedge[\mathrm{G} 26]$

$\mathrm{MD}=0.657+0.2 *(1-0.657)=0.7256$

4. $[\mathrm{G} 17] \wedge[\mathrm{G} 24] \wedge[\mathrm{G} 25] \wedge[\mathrm{G} 26] \wedge[\mathrm{G} 27]$

$\mathrm{MD}=0.7256+0.3 *(1-0.7256)=0.80792$

5. $[\mathrm{G} 03] \wedge[\mathrm{G} 17] \wedge[\mathrm{G} 24] \wedge[\mathrm{G} 25] \wedge[\mathrm{G} 26] \wedge[\mathrm{G} 27]$

$\mathrm{MD}=0.80792+0.2 *(1-0.80792)=0.846336$

6. $[\mathrm{G} 03] \wedge[\mathrm{G} 17] \wedge[\mathrm{G} 24] \wedge[\mathrm{G} 25] \wedge[\mathrm{G} 26] \wedge[\mathrm{G} 27] \wedge[\mathrm{G} 28]$

$\mathrm{MD}=0.846336+0.1 *(1-0.846336)=0.8617024$

7. $[\mathrm{G} 03] \wedge[\mathrm{G} 17] \wedge[\mathrm{G} 24] \wedge[\mathrm{G} 25] \wedge[\mathrm{G} 26] \wedge[\mathrm{G} 27] \wedge[\mathrm{G} 28] \wedge[\mathrm{G} 29]$

$\mathrm{MD}=0.86170244+0.1 *(1-0.8617024)=0.87553216$

8. $[\mathrm{G} 03] \wedge[\mathrm{G} 17] \wedge[\mathrm{G} 24] \wedge[\mathrm{G} 25] \wedge[\mathrm{G} 26] \wedge[\mathrm{G} 27] \wedge[\mathrm{G} 28] \wedge[\mathrm{G} 29] \wedge[\mathrm{G} 30]$

$\mathrm{MD}=0.87553216+0.1 *(1-0.87553216)=0.887978944$

Lalu dilakukan perkalian nilai keseluruhan MB dan nilai keseluruhan MD untuk mendapatkan nilai Certainty Factor dari keseluruhan gejala menggunakan persamaan (6).

$C F[h, e]=C F(e) x C F($ rule $)=0.999999676 * 0.887978944=0.8879786563$ 
Langkah terakhir tentukan presentase nilai kepercayaan dengan mengalikan $100 \%$ nilai Certainty Factor diatas menggunakan persamaan (7).

$$
C F_{\text {persentase }}=C F * 100 \%=0.8879786563 * 100 \%=88.8 \%
$$

Pada Tabel 2 disajikan keseluruhan nilai Kepercayaan dan Ketidakpercayaan untuk setiap jenis hama. Perhitungan secara manual menggunakan metode Certainty Factor berdasarkan gejala-gejala tersebut yang terjadi, maka diperoleh 7 hama yang menyerang tanaman kelapa sawit.

Tabel 2. Perhitungan Manual dengan Certainty Factor

\begin{tabular}{|l|l|l|l|l|l|}
\hline Rule & \multicolumn{1}{|c|}{ Hama } & MB & MD & CF & \multicolumn{1}{c|}{ CF\% } \\
\hline R1 & Ulat Api & 0.99999 & 0.85597 & 0.85597 & $85.6 \%$ \\
\hline R2 & Ulat Bulu & 0.99999 & 0.86221 & 0.86221 & $86.22 \%$ \\
\hline R3 & Ulat Kantong & 0.99999 & 0.86936 & 0.86936 & $86.94 \%$ \\
\hline R4 & Kumbang Tanduk & 0.99999 & 0.80567 & 0.80567 & $80.57 \%$ \\
\hline R5 & Rayap & 0.99999 & 0.88797 & 0.88797 & $88.8 \%$ \\
\hline R6 & Tikus Belukar & 0.99999 & 0.82154 & 0.82154 & $82.15 \%$ \\
\hline R7 & Babi Hutan & 0.99999 & 0.70140 & 0.70140 & $70.14 \%$ \\
\hline
\end{tabular}

Berdasarkan data dan informasi dari Dinas Perkebunan Provinsi Kalimantan Timur bahwa pada tahun 2018 terdapat 6 hama yang paling banyak menyerang perkebunan kelapa sawit di Provinsi Kalimantan Timur yaitu, tikus dan babi hutan yang merupakan hama mamalia, serta hama serangga seperti kumbang tanduk dan ulat pemakan daun kelapa sawit (UPDKS) yaitu ulat api, ulat kantong dan ulat bulu. Pada penelitian sistem pakar identifikasi hama kelapa sawit dengan Certainty Factor ini diperoleh jenis hama yang juga menyerang kelapa sawit yaitu rayap. Dengan demikian, terlihat pada Tabel 2 berdasarkan perhitungan Certainty Factor untuk menghitung faktor kepastian dari gejala serangan hama tanaman kelapa sawit diperoleh hasil sebanyak 7 hama yang menyerang perkebunan kelapa sawit di Provinsi Kalimantan Timur.

Penggunaan aplikasi sistem pakar identifikasi hama kelapa sawit dengan cara memilih gejala yang sama seperti pada perhitungan manual, maka pada sistem aplikasi diperoleh hasil yang sama dengan perhitungan manual menggunakan metode Certainty Factor. Gambar 2 adalah hasil konsultasi pada sistem pakar identifikasi hama kelapa sawit yang menampilkan hasil konsultasi user berupa identifikasi hama yang menyerang tanaman kelapa sawit yaitu hama rayap Coptotermes curvignathus, disertasi solusi yang diberikan oleh sistem untuk pengendalian hama yang menyerang pada kelapa sawit tersebut.

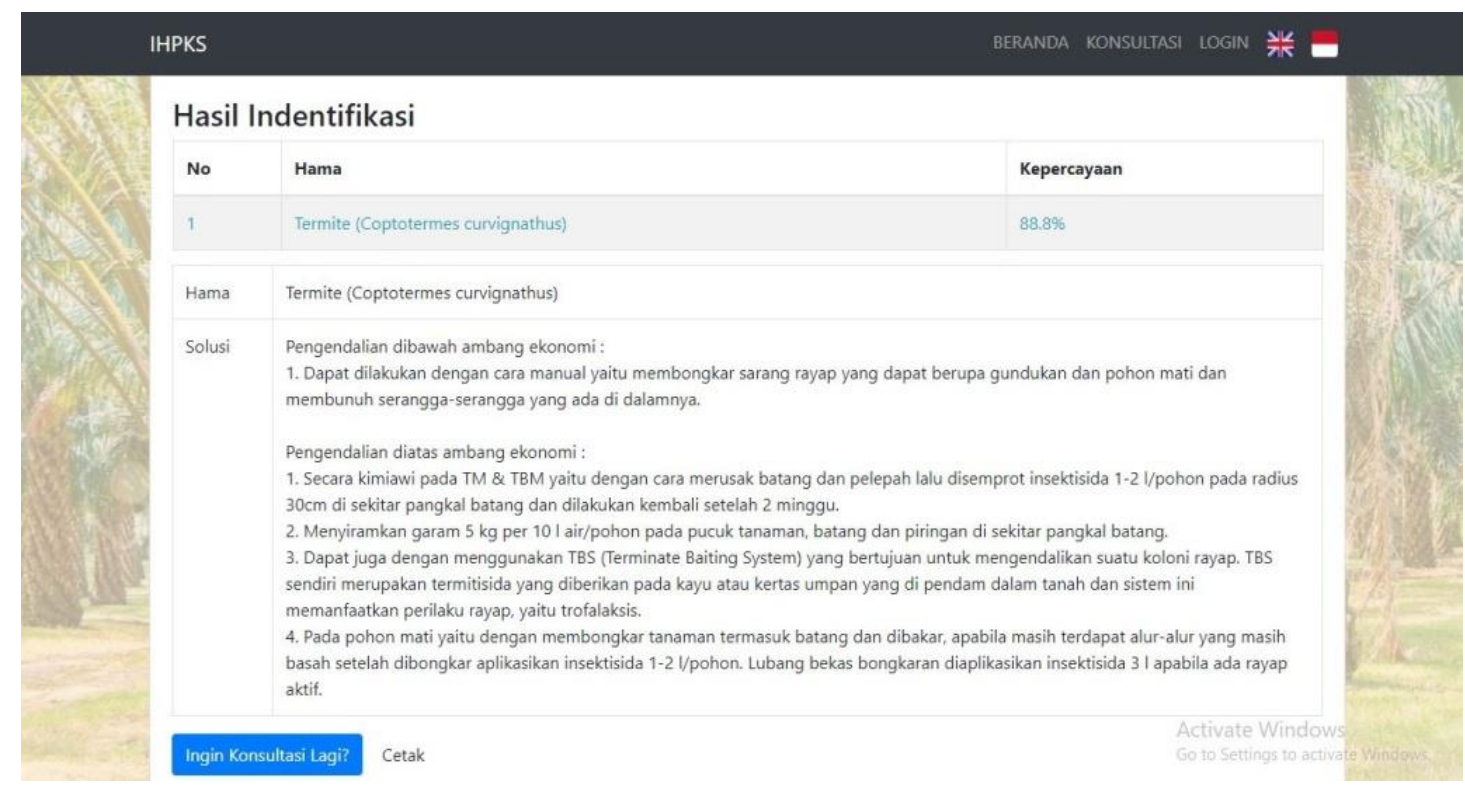

Gambar 2. Hasil Konsultasi

\section{Kesimpulan dan saran}

Penelitian ini menghasilkan identifikasi 7 (tujuh) hama yang menyerang tanaman kelapa sawit di Provinsi Kalimantan Timur, yaitu ulat api Setothosea asigna, ulat bulu Dasychira inclusa, ulat kantong Metisa plana, kumbang tanduk Oryctes rhinoceros, rayap Coptotermes curvignathus, tikus belukar Rattus 
tiomanicus, dan babi hutan Sus crofa. Sistem pakar identifikasi hama kelapa sawit ini menggunakan Certainty Factor untuk menghitung kepastian serangan hama kelapa sawit, sehingga diperoleh hasil serangan hama terbesar pada kelapa sawit yaitu hama rayap Coptotermes curvignathus sebesar $88.8 \%$. Sistem juga memberikan solusi penanganan dan pengendalian terhadap hama yang menyerang kelapa sawit. Penelitian dimasa mendatang disarankan dapat dikembangkan menggunakan metode penelusuran yang lain agar memberikan hasil yang lebih akurat.

\section{Daftar Pustaka}

[1] J. Widians, M. Taruk, Y. Fauziah, and H. Setyadi, "Decision Support System on Potential Land Palm Oil Cultivation using Promethee with Geographical Visualization," in Journal of Physics: Conference Series, 2019, vol. 1341, no. 4: IOP Publishing, p. 042011.

[2] H. Hamdani and R. Wardoyo, "A review on fuzzy multi-criteria decision making land clearing for oil palm plantation," International Journal of Advances in Intelligent Informatics, vol. 1, no. 2, pp. 75-83, 2015.

[3] Y. Fauzi, Y. E. Widyastuti, I. Satyawibawa, and R. H. Paeru, Kelapa sawit. Penebar Swadaya Grup, 2012.

[4] H. Aini, H. Haviluddin, E. Budiman, M. Wati, and N. Puspitasari, "Prediksi Produksi Minyak Kelapa Sawit Menggunakan Metode Backpropagation Neural Network," Sains, Aplikasi, Komputasi dan Teknologi Informasi, vol. 1, no. 1, pp. 24-33, 2019.

[5] I. Rosalyn, "Indeks Keanekaragaman Jenis Serangga Pada Pertanaman Kelapa Sawit (Elaeis Guineensis Jacq.) Di Kebun Tanah Raja Perbaungan PT. Perkebunan Nusantara III," 2007.

[6] J. Handoko, H. Fauzana, and A. Sutikno, "Populasi dan intensitas Serangan Hama Kumbang Tanduk (Oryctes rhinoceros Linn.) pada Tanaman Kelapa Sawit (Elaeis guineensis Jacq.) Belum Menghasilkan," Riau University, 2017.

[7] A. G. Pratama, A. H. Wibowo, and S. Nurhalimah, "Metode Forward Chaining dalam Sistem Pakar Diagnosis Penyakit pada Tanaman Kelapa Sawit," Prosiding SISFOTEK, vol. 3, no. 1, pp. 82-86, 2019.

[8] R. Fauzan and A. V. Prananda, "Expert System for Diagnosing Palm Tree Diseases and Pests using Forward Chaining and Certainty Factor," Kinetik: Game Technology, Information System, Computer Network, Computing, Electronics, and Control, vol. 3, no. 1, pp. 27-34, 2017.

[9] J. A. Widians, N. Puspitasari, and A. Febriansyah, "Disease Diagnosis System Using Certainty Factor," in 2019 International Conference on Electrical, Electronics and Information Engineering (ICEEIE), 2019, vol. 6: IEEE, pp. 303-308.

[10] J. A. Widians, "Aplikasi Sistem Pakar Identifikasi Penyakit Pada Tanaman Pisang," Informatika Mulawarman: Jurnal Ilmiah Ilmu Komputer, vol. 6, no. 1, pp. 45-49, 2016.

[11] J. A. Widians and I. A. Saputra, "Aplikasi Sistem Pakar Skoring Tes IQ menggunakan Alat CFIT," Sebatik, vol. 17, no. 1, pp. 1-5, 2017.

[12] J. A. Widians, M. Wati, and J. Juriah, "Aplikasi Sistem Pakar Tingkat Depresi Pada Remaja Menggunakan Certainty Factor," SEMNASTEKNOMEDIA ONLINE, vol. 5, no. 1, pp. 3-6-79, 2017.

[13] J. A. Widians and A. Utomo, "Sistem Pakar Diagnosa Dyspepsia Dengan Certainty Factor," SEMNASTEKNOMEDIA ONLINE, vol. 3, no. 1, pp. 3-6-25, 2015.

[14] J. A. Widians, N. Puspitasari, and U. Ameilia, "Expert System of Black Orchid Cultivation using Certainty Factor Method," in 2018 2nd East Indonesia Conference on Computer and Information Technology (EIConCIT), 2018: IEEE, pp. 35-40.

[15] H. R. Hatta, S. Maharani, Z. Arifin, M. Annisa, M. R. Ibrahim, and R. M. Akhyar, "Perancangan Aturan Penentuan Kecocokan Tanaman Untuk Pertanian Lahan Kering Menggunakan Metode Forward Chaining," in Prosiding SAKTI (Seminar Ilmu Komputer dan Teknologi Informasi), 2017, vol. 2, no. 2, pp. 59-64. 